\title{
molecules
}

ISSN 1420-3049

www.mdpi.com/journal/molecules

Communication

\section{Synthesis and Herbicidal Activity of New Hydrazide and Hydrazonoyl Derivatives}

\section{František Šeršeň ${ }^{1, *}$, Fridrich Gregán̆ ${ }^{2}$, Matúš Peško ${ }^{3}$, Dana Dvoranová ${ }^{4}$, Katarína Král'ová ${ }^{1}$,} Zuzana Matkovičová ${ }^{1}$, Juraj Gregáň ${ }^{5,6, *}$ and Jana Donovalová ${ }^{1}$

1 Institute of Chemistry, Faculty of Natural Sciences, Comenius University in Bratislava, Mlynská dolina, Bratislava 842 15, Slovakia; E-Mails: kralova@fns.uniba.sk (K.K.); matkovicova@fns.uniba.sk (Z.M.); donovalova@fns.uniba.sk (J.D.)

2 Department of Chemistry, Faculty of Natural Sciences, Matej Bell University, Tajovského 40, Banská Bystrica 974 01, Slovakia; E-Mail: Fridrich.Gregan@umb.sk

3 Department of Environmental Ecology, Faculty of Natural Sciences, Comenius University in Bratislava, Mlynská dolina, Bratislava 842 15, Slovakia; E-Mail: pesko@fns.uniba.sk

4 Institute of Physical Chemistry and Chemical Physics, Faculty Chemical and Food Technology, Slovak University of Technology in Bratislava, Radlinského 9, Bratislava 812 37, Slovakia; E-Mail: dana.dvoranova@stuba.sk

5 Department of Genetics, Faculty of Natural Sciences, Comenius University in Bratislava, Mlynská dolina, Bratislava 842 15, Slovakia

6 Department of Chromosome Biology, MFPL, University of Vienna, Dr. Bohr-Gasse 7, Vienna 1030, Austria

* Authors to whom correspondence should be addressed; E-Mails: sersen@fns.uniba.sk (F.S.); juraj.gregan@univie.ac.at (J.G.); Tel.: +421-260-296 (ext. 412) (F.Š.); +421-260-296 (ext. 158) (J.G.); Fax: +421-2-65-429-064 (F.Š. \& J.G.).

Academic Editor: Roman Dembinski

Received: 18 June 2015 / Accepted: 31 July 2015 / Published: 4 August 2015

\begin{abstract}
Three new hydrazide and five new hydrazonoyl derivatives were synthesized. The chemical structures of these compounds were confirmed by ${ }^{1} \mathrm{H}-\mathrm{NMR}$, IR spectroscopy and elemental analysis. The prepared compounds were tested for their activity to inhibit photosynthetic electron transport in spinach chloroplasts and growth of the green algae Chlorella vulgaris. $\mathrm{IC}_{50}$ values of these compounds varied in wide range, from a strong to no inhibitory effect. EPR spectroscopy showed that the active compounds interfered with intermediates $\mathrm{Z}^{\bullet} / \mathrm{D}^{\bullet}$, which are localized on the donor side of photosystem II. Fluorescence
\end{abstract}


spectroscopy suggested that the mechanism of inhibitory action of the prepared compounds possibly involves interactions with aromatic amino acids present in photosynthetic proteins.

Keywords: green algae; $N^{\prime}$-[2,6-dinitro-4-(trifluoromethyl)phenyl]hydrazides; $N^{\prime}$-[2,6-dinitro-4[trifluoromethyl)phenyl]hydrazonoyl derivatives; photosynthesis inhibition; spinach chloroplasts

\section{Introduction}

Hydrazides, hydrazonoyl halides and hydrazonoyl cyanides exhibit a wide spectrum of biological activities including antimicrobial [1-7], antifungal [8,9], antibacterial [8,10], antituberculotic [5,11], anticancer, anti-inflammatory and analgesic effects [12]. The biological activities and applications of hydrazone derivatives were comprehensively reviewed by Rollas and Küçükgüzel [13], Kumar and Narasimhan [14] and Narang et al. [15]. Some hydrazine derivatives induced DNA fragmentation [16] and exhibited mutagenic activity [17,18]. Hydrazides of aromatic aldehydes were found to be phytotoxic with specificity for Amaranthus retroflexus L. by absorption through the foliage [19]. $N^{\prime}$-(4-methylphenylsulfonyl)-3-bromothiophene-2-carbohydrazonoyl chloride and 3-(4-benzyl-1-yl)-1(toluene-4-sulfonyl)-1H-thieno[3,2-c]pyrazole were synthesized as dopamine D3 receptors [20]. Maleic hydrazide has been used in agriculture as a major commercial herbicide since 1950, however, later studies showed that it exhibits mutagenic effects [21,22].

Hydrazine is an electron donor to the oxidizing side of photosystem II (PSII) and in photosynthesis it supports a light-dependent electron flow in chloroplasts inhibited at the water-oxidizing complex (WOC) [23]. Treatment of thylakoids with hydrazine permits a high population of the redox states $\mathrm{S}_{0}$, $\mathrm{S}_{-1}$, and $\mathrm{S}_{-2}$ in the water oxidase, a complex enzyme which integrates a photochemical reaction centre, PSII, and a catalytic centre, a manganese cluster [24]. According to Förster and Junge [25], two bridging ligands, possible $\mathrm{Cl}^{-}$or $\mathrm{OH}^{-}$, which normally connect two $\mathrm{Mn}$ nuclei, can be substituted by two molecules of hydrazine when the WOC resides in state $\mathrm{S}_{1}$. The reactivity of hydrazine with PSII depends strongly on redox state of WOC [26]. Treatment of chloroplasts with high hydrazine concentration $\left(1 \mathrm{mmol} / \mathrm{dm}^{3}\right)$ resulted in complete inhibition of water splitting reaction under flash light [27]. The dichlorophenol-indophenol (DCPIP) reduction by PSII in chloroplasts prepared from leaves of Phaseolus vulgaris L. was significantly decreased by maleic hydrazide treatment, while ferricyanide reduction activity was significantly accelerated and it was assumed that the site of action of maleic hydrazide is not situated in PSII but it is between cytochrome and plastocyanin on the donor side of PSI [28]. $N^{\prime}$-phtalohydrazine and dichlorophenylhydrazine were found to be relatively efficient donors to PSII, although less efficient than hydrazobenzene [29]. The photosynthetic electron transpot (PET) inhibiting activity of hydrazones derived from furo[3,2- $b]$ pyrrole-5-carboxhydrazides by their reactions with substituted furan-2-carboxaldehydes or thiophene-2-carboxaldehyde varied in the range from 0.071 to $2.060 \mathrm{mmol} / \mathrm{dm}^{3}$ and application of these compounds at concentrations $1-100 \mu \mathrm{mol} / \mathrm{dm}^{3}$ mostly did not affect significantly chlorophyll content in Chlorella vulgaris [30]. On the other hand, mixtures containing hydrazone compounds and copper were patented as suitable for controlling the growth of algae [31]. The ionophore carbonylcyanide-4-(trifluoromethoxy)phenylhydrazone acts as an uncoupler of ATP-ase, because it disrupts proton transport-coupled ATP synthesis [32,33]. 
The synthesis of novel hydrazone derivatives is perspective because of their potential use as antimicrobial or therapeutical compounds. In our current work we prepared three new derivatives of hydrazide and five hydrazonoyl derivatives and analyzed their inhibitory effect on PET in spinach chloroplasts by Hill reaction, fluorescence and EPR spectroscopy.

\section{Results and Discussion}

\subsection{Chemistry}

The starting compounds for the synthesis of organic hydrazonoyl chlorides $\mathbf{3 b}, \mathbf{3 c}, \mathbf{3 d}, \mathbf{3 e}$ and one hydrazonoyl cyanide $\mathbf{4 f}$, were carbohydrazides and acethydrazide 1a-1c. These hydrazides were prepared in high yields by nucleophilic substitution reactions of the corresponding methyl esters with hydrazine hydrate in propanol at $80{ }^{\circ} \mathrm{C}$ for $10-12 \mathrm{~h}$ as described in [34-37]. $N$-substituted hydrazides 2a, 2b, 2c were prepared by nucleophilic substitution reactions of 1-chloro-4-trifluoromethyl-2,6-dinitrobenzene and the corresponding hydrazides $\mathbf{1}$ (Scheme 1) in anhydrous dimethoxyethane with triethylamine as catalyst, for $2-3 \mathrm{~h}$ at room temperature [38-40]. The yields of these products were $74 \%-80 \%$, after recrystallization.

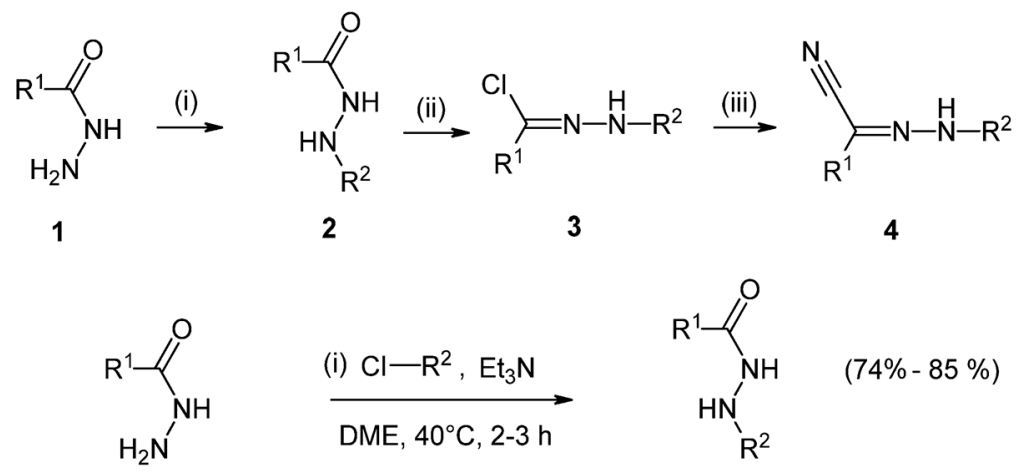

1a, 1b, 1c

2a, 2b, 2c

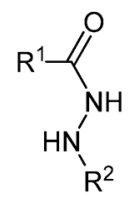

$2 b, 2 c, 2 d, 2 e$<smiles>[R]NN=C([R])Cl</smiles>

3f

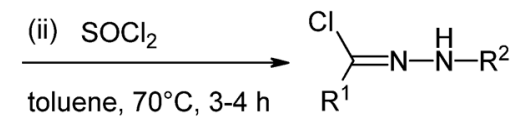

$(56 \%-67 \%)$ $\underset{\text { EtOH, } \mathrm{H}_{2} \mathrm{O} \text {, r.t., } 6 \mathrm{~h}}{\stackrel{\text { (iii) } \mathrm{KCN}}{\longrightarrow}}$
$3 b, 3 c, 3 d, 3 e$<smiles>[R]NN=C([R])C#N</smiles>

$(63 \%)$

Scheme 1. Preparation of $N^{\prime}$-substituted hydrazides 2 (2a, 2b, 2c), $N^{\prime}$-substituted hydrazonoyl chlorides 3 (3b, 3c, 3d, 3e) and $N^{\prime}$-substituted hydrazonoyl cyanide 4 (4f); (i), (ii), (iii), reactants and reaction conditions; $\mathbf{1 a}, \mathbf{2} \mathbf{a}, \mathrm{R}^{1}=4$-methoxyphenyl, $\mathbf{1 b}, \mathbf{2} \mathbf{b}, \mathbf{3 b}, \mathrm{R}^{1}=$ 4-tert-butylphenyl, 1c, 2c, 3c, $\mathrm{R}^{1}=$ methyl; 2d, 3d, $\mathrm{R}^{1}=4$-fluorophenyl, 2e, 3e, $\mathrm{R}^{1}=$ thiophene-2-yl, 3f, 4f, $\mathrm{R}^{1}=$ naphtalene-2-yl; $\mathrm{R}^{2}=$ 2,6-dinitro-4-(trifluoromethyl)phenyl, for compounds 2, 3 and 4 . Yields of products (\%) are indicated in brackets. Compounds 1a, $\mathbf{1 b}$ and $\mathbf{1 c}$ were prepared according to literature [34-37] and compounds $\mathbf{2 e}, \mathbf{2 d}$, and $\mathbf{3 f}$ were obtained from Tauchem (Bratislava, Slovakia). 
Hydrazonoyl chlorides $\mathbf{3 b}, \mathbf{3 c}, \mathbf{3 d}$ and $\mathbf{3 e}$ were prepared by nucleophilic substitution reaction of $N^{\prime}$-substituted hydrazides $\mathbf{2 a}, \mathbf{2 b}$ and $\mathbf{2 c}$ and thionyl chloride [40-43]. The reaction (Scheme 1) was carried out for $3-4 \mathrm{~h}$ in toluene, at $70{ }^{\circ} \mathrm{C}$. The yields of products were $56 \%-67 \%$ after purification. Hydrazonoyl cyanide $\mathbf{4 f}$ was prepared from corresponding hydrazonoyl chloride as starting compound and potassium cyanide in an ethanol-water mixture [40]. The yield was $63 \%$ after recrystallization from cyclohexane. All prepared compounds were solid compounds. Hydrazonoyl chlorides and hydrazonoyl cyanide were colored. Structure of all newly prepared compounds was confirmed by ${ }^{1} \mathrm{H}-\mathrm{NMR}$, IR spectroscopy and elemental analysis.

\subsection{Inhibition of Photosynthetic Electron Transport (PET) in Spinach Chloroplasts}

Five of the studied compounds inhibited PET in spinach chloroplasts. However, their inhibitory activity varied over a wide range. The $\mathrm{IC}_{50}$ values of the studied compounds are presented in Table 1 (second column). The most effective derivative was $N^{\prime}$-[2,6-dinitro-4-(trifluoromethyl)phenyl]thiophene-2carbohydrazonoyl chloride (3e) with an $\mathrm{IC}_{50}=2.34 \mu \mathrm{mol} / \mathrm{dm}^{3}$, which is comparable to the classical herbicide diuron (3-(3,4-dichlorophenyl)-1,1-dimethylurea; DCMU) with an $\mathrm{IC}_{50}=1.9 \mu \mathrm{mol} / \mathrm{dm}^{3}$ [44]. The high activity of compound $\mathbf{3 e}$ may be associated with the presence of the thiophene nucleus in this compound because the free electron pair of the sulphur in the thiophene moiety could interact with constituents of the photosynthetic apparatus via hydrogen bonds. On the other hand, no PET inhibition was observed for compounds $\mathbf{2 a}, \mathbf{2 c}$ and $\mathbf{4 f}$. In our current study, we have chosen 4-trifluoromethyl-2,6dinitrophenyl substitution for $N^{\prime}$-substituted hydrazides and hydrazonoyl derivatives based on our previous observations that electron-withdrawing substituents, such as $\mathrm{CF}_{3}$, showed effective PET inhibition [45-48].

Table 1. $\mathrm{IC}_{50}$ values $\left(\mu \mathrm{mol} / \mathrm{dm}^{3}\right)$ of studied hydrazide and hydrazonoyl derivatives.

\begin{tabular}{ccc}
\hline Compound & PET Inhibition in Chloroplasts & Growth Inhibition of Chlorella vulgaris \\
\hline $\mathbf{2 a}$ & no inhibition & no inhibition \\
$\mathbf{2 b}$ & 18.0 & 25.87 \\
$\mathbf{2 c}$ & no inhibition & 8.01 \\
$\mathbf{3 b}$ & 146.0 & 17.58 \\
$\mathbf{3 c}$ & 2213 & 10.32 \\
$\mathbf{3 d}$ & 61.4 & 13.32 \\
$\mathbf{3 e}$ & 2.34 & 12.30 \\
$\mathbf{4 f}$ & no inhibition & no inhibition \\
DCMU & $1.9 *$ & $7.3 * *$ \\
\hline \multicolumn{3}{c}{} \\
\end{tabular}

Next, we attempted to determine the site of action of the studied compounds by studying the emission spectra of chlorophyll in spinach chloroplasts treated with the studied compounds. The fluorescence spectra of spinach chloroplasts treated with compounds under study are presented in Figure 1 . We identified the emission peak at $684 \mathrm{~nm}$ corresponding to $\mathrm{Chl}$, located in the pigment protein complexes of the photosystem PSII and a shoulder at $739 \mathrm{~nm}$ which corresponds to fluorescence of Chla located in the pigment protein complexes of the PSI [50]. This experiment showed that the compounds which inhibited the PET in spinach chloroplasts quenched the fluorescence of chlorophyll molecules present in the pigment protein complexes of both photosystems. On the other hand, the compounds which did 
not inhibit PET (2a, 2c and 4f) increased the fluorescence of chlorophyll. This effect may be caused by defects in photoreduction of QA. A similar effect has been observed by Haveman et al. [29] on PSII particles treated with hydrazobenzene. Based on these findings, we can assume that the sites of action of the studied compounds are both photosynthetic centers PSI and PSII.

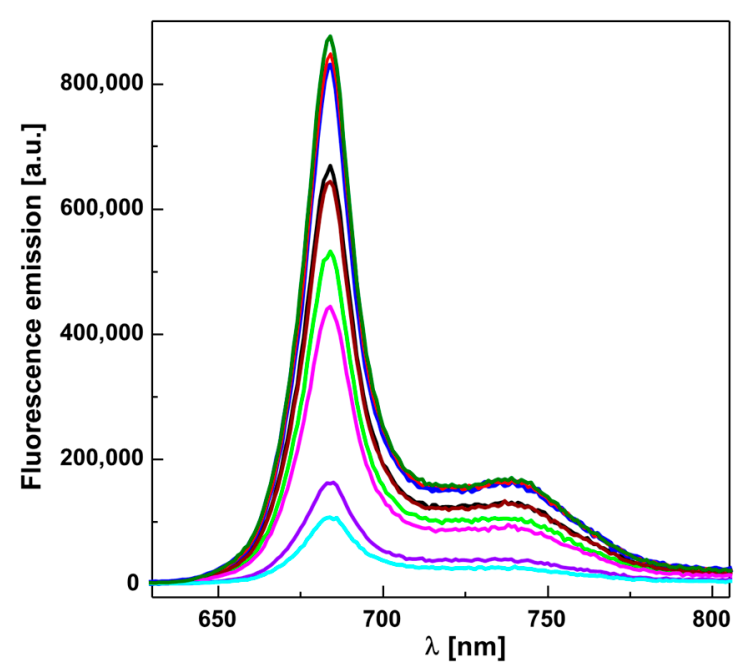

Figure 1. Fluorescence emission spectra of untreated spinach chloroplasts and those treated with $5 \mu \mathrm{mol} / \mathrm{dm}^{3}$ of studied compounds (from top to bottom: $\mathbf{4 f}$ - olive; $\mathbf{2 c}$ - red; $\mathbf{2 a}$ - blue; control sample — black; 3c — wine; 3e — green; 3b-magenta; 3d-violet; 2b-cyan).

We speculated that the mechanism of inhibitory action of the studied compounds may involve their interaction with proteins present in the photosynthetic reaction centers. To test our hypothesis, we analyzed the effect of studied compounds on the fluorescence of aromatic amino acids present in spinach chloroplasts. Quenching of the fluorescence was observed when compound 3e was added to spinach chloroplasts (Figure 2). A similar effect was observed with other tested compounds (data not shown).

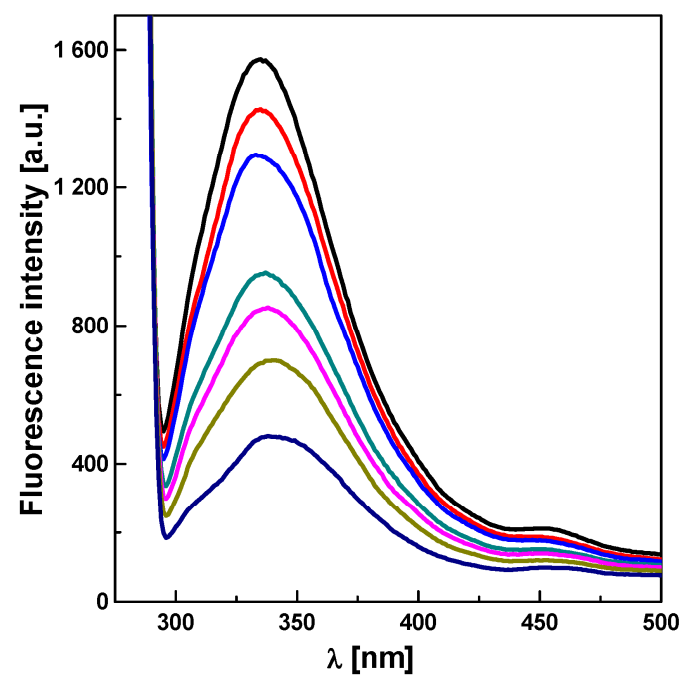

Figure 2. Effect of $N^{\prime}$-[2,6-dinitro-4-(trifluoromethyl)phenyl]thiophene-2-carbohydrazonoyl chloride on fluorescence of chloroplast amino acids. Compound $\mathbf{3 e}$ was added to spinach chloroplasts to a final concentration of $0,10,20,30,40,60,80 \mu \mathrm{mol} / \mathrm{dm}^{3}$ (from top to bottom). 
Using EPR experiments, we found that studied compounds inhibiting the PET immediately decreased the intensity of both EPR signals originating from the intermediates $Z^{\circ}$ and $\mathrm{D}^{\circ}$, alternatively, only $\mathrm{D}^{\circ}$ (Figure 3). The EPR spectrum of the intermediate $\mathrm{D}^{\bullet}(\mathrm{g}=2.0046, \Delta \mathrm{BPP}=2 \mathrm{mT})$, which corresponds to the radical of tyrosine at position 161 in the $\mathrm{D}_{2}$ protein of PSII [51], is shown as black line in the EPR spectrum of untreated chloroplasts in the dark (Figure 3A, black line). The increase of intensity in the EPR spectra of untreated chloroplasts in the light represents EPR signal of the intermediate $Z^{*}$ (Figure 3A, difference between black and red lines; $g=2.0046, \Delta B_{P P}=2 \mathrm{mT}$ ), which corresponds to the radical of tyrosine situated at position 161 in the $\mathrm{D}_{1}$ protein of PSII [52]. We found that the studied compounds had different impacts on the intermediates $Z^{*} / D^{*}$. Substances that showed no inhibition of the Hill reaction (2a and 2c) exhibited very little effect on intermediates $Z{ }^{*} / D^{\circ}$ which resulted in only minor changes in the EPR spectra of chloroplasts treated with these compounds. EPR spectra of chloroplasts treated with compound 2a are shown in the Figure 3B. We observed a similar effect in chloroplasts treated with compound 2c (data not shown). Compounds that inhibited the Hill reaction affected differently function of intermediates $\mathrm{Z}^{*} / \mathrm{D}^{\bullet}$. Almost complete disappearance of the signal corresponding to $\mathrm{D}^{\bullet}$ was observed in EPR spectra of chloroplasts treated with compounds $\mathbf{2 b}, \mathbf{3 b}, \mathbf{3} \mathbf{c}$ and $\mathbf{3 d}$ (Figure 3C, black line), whereas the signal from the intermediate $Z^{*}$ remained unchanged (Figure $3 \mathrm{C}$ red line). EPR spectra of chloroplasts treated with compound $\mathbf{2 b}$ are shown in the Figure $3 \mathrm{C}$. We observed a similar effect in chloroplasts treated with compound $\mathbf{3 b}, \mathbf{3} \mathbf{c}$ and $\mathbf{3 d}$ (data not shown). On the other hand, compounds $\mathbf{3 e}$ and $\mathbf{4 f}$ interfered with both intermediates $Z^{\circ} / \mathrm{D}^{\bullet}$ which is demonstrated by the complete disappearance of both signals in the EPR spectra of chloroplasts treated with these agents (Figure 3D,E, black and red lines). One possible explanation is that the interaction of studied compounds with intermediates $Z^{*} / \mathrm{D}^{\bullet}$ resulted in interruption of electron transfer from PSII to PSI that caused a large increase of the EPR signal $(\mathrm{g}=2.0026, \Delta \mathrm{BPP}=$ $1 \mathrm{mT}$ ) corresponding to the core of PSI $\left(\mathrm{P} 680^{+}\right)$, thus oxidized form of Chla dimer [53] (Figure 3C,D, red lines). The compound $\mathbf{4 f}$ oxidized P680 already in the dark (Figure 3E, black line).

Interestingly, in chloroplasts in which PET was inhibited by addition of active compounds (i.e., $\mathbf{2 b}$, $\mathbf{3 b}, \mathbf{3 c}, \mathbf{3 d}$ and 3e), a recovery of the PET nearly to the original levels was observed after the addition of DPC. This experiment suggests that the studied compounds may act at the donor side of PSII in the complex decomposing water or at the sites of $Z^{\circ} / D^{\bullet}$ intermediates. Our finding is consistent with previous findings of Heath [23] and Förster and Junge [25]. In order to determine whether PET through PSI is damaged, we carried out experiments with chloroplasts treated with the studied compounds and $\mathrm{DCPIPH}_{2}$, an artificial electron donor operating in plastocyanin on the donor side of PSI and using methyl viologen as the final artificial electron acceptor of PSI. We found that in such treated chloroplasts, with the exception of the compound $4 \mathbf{f}$ (which caused oxidation of P680 already in the dark), PET through PSI was not interrupted. Thus, it is likely the studied compounds have other site of action, for example, cytochrome $b_{6} f$ complex, located between the PSI and PSII. Interestingly, a similar conclusion was published by Haveman et al. [29], who found that hydrazobenzene, which is structurally similar to compounds synthesized in our current study, can be oxidized in at least two photoreactions. In the first reaction, it acts as an efficient donor for PSII and this reaction is inhibited by $5 \mu \mathrm{M}$ DCMU, while a second hydrazobenzene-DCPIP reaction, which is not inhibited by DCMU, is presumably catalyzed via an oxidized component of the redox chain between the primary stable electron acceptor of PSII and the quencher of chlorophyll fluorescence and PSI. 


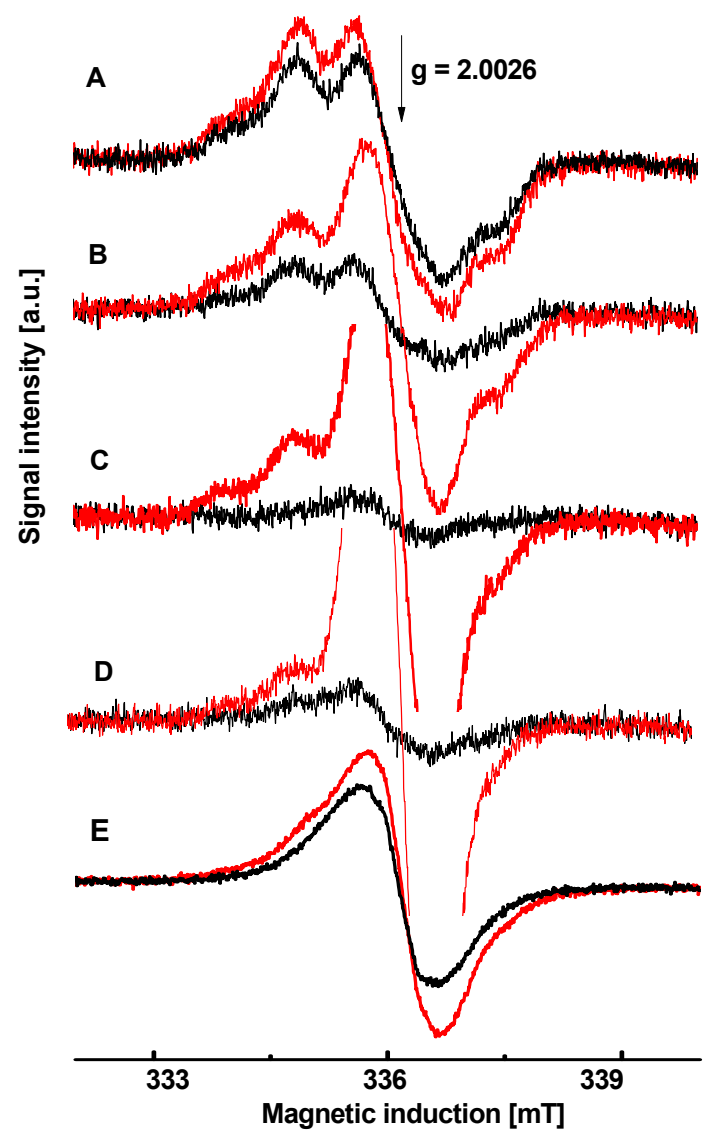

Figure 3. EPR spectra of untreated spinach chloroplasts (A) and those treated with $0.05 \mathrm{~mol} / \mathrm{dm}^{3}$ of $\mathbf{2 a}(\mathbf{B}) ; \mathbf{2} \mathbf{b}(\mathbf{C}) ; 3 \mathbf{e}(\mathbf{D})$ and $\mathbf{4 f}(\mathbf{E})$. Black curves indicate spectra registered in the dark. Red curves indicate spectra registered in the light.

\subsection{Inhibition of Algae Growth}

To determine a long-time effect of the studied compounds on a photosynthetic organism, we analyzed the effect of these compounds on growth of the green algae Chlorella vulgaris monitoring chlorophyll concentrations in algal suspensions according to Pavlíková et al. [54]. Six compounds effectively inhibited the growth of algae (Table 1, third column). For an illustration, the antialgal activity of DCMU is about $7.3 \mu \mathrm{mol} / \mathrm{dm}^{3}$ [49]. Interestingly, the most effective compound was $\mathbf{2 c}$, which did not inhibit PET in spinach chloroplasts. This suggests that the compound $\mathbf{2 c}$ acts in algae on targets other than photosynthetic centers, for example, it may inhibit enzymes involved in biosynthesis of chlorophyll or stimulate some other enzymes involved in its degradation.

\section{Experimental Section}

\subsection{General Information}

Ethyl acetate p.a., $n$-hexane p.a., propanol p.a., ethanol p.a., 2,6-dichlorophenol-indophenol (DCPIP), 1,5-diphenylcarbazide (DPC), TRIS, $\mathrm{MgCl}_{2}$, saccharose, 1,1'-dimethyl-4,4'-bipyridinium dichloride hydrate (methyl viologen), dimethoxyethane (DME), triethylamine, dimethylsulfoxide p.a. (DMSO), 3-(3,4-dichlorophenyl)-1,1-dimethylurea (DCMU) and thionyl chloride were purchased from Centralchem 
(Bratislava, Slovakia). 1-Chloro-4-trifluoromethyl-2,6-dinitrobenzene was purchased from Alfa Aesar (Ward Hill, MA, USA). 4-Ethoxybenzohydrazide, acethydrazide and 4-tert-butylbenzohydrazide were prepared according to literature [34-37]. $N^{\prime}$-[2,6-Dinitro-4-(trifluoromethyl)phenyl]thiophene-2carbohydrazide (2e), $N^{\prime}$-[2,6-dinitro-4-(trifluoromethyl)phenyl]-4-fluorobenzohydrazide (2d) and $N^{\prime}$ [2,6-dinitro-4-(trifluoromethyl)]-2-naphthohydrazonoyl chloride (3f) were purchased from Tauchem (Bratislava, Slovakia).

Melting points were determined on a Kofler hot plate apparatus and are uncorrected. IR spectra were obtained on a NICOLET NEXUS 470 spectrophotometer in $\mathrm{KBr}$. Elemental analyses were obtained on Elemental Analyzer Carlo Erba CHNS-OEA 1108. ${ }^{1} \mathrm{H}-\mathrm{NMR}$ spectra at $300 \mathrm{MHz}$ were obtained on Varian Gemini 2000 spectrophotometer in DMSO- $d_{6}$ with tetramethylsilane as an internal standard. The purity of prepared compounds and course of reactions were checked on Merck TLC Silica gel 60 $\mathrm{F}_{254}$ plates in ethyl acetate- $n$-hexane as the mobile phase.

\subsection{Synthesis}

3.2.1. General Procedure for Synthesis of $N^{\prime}$-[2,6-dinitro-4-(trifluoromethyl)phenyl]hydrazides 2a, 2b, 2c

A solution of 1-chloro-2,6-dinitro-4-(trifluoromethyl)benzene $(10 \mathrm{mmol})$ in 1,2-dimethoxyethane $(20 \mathrm{~mL})$ was added dropwise to a stirred solution of of $N^{\prime}$-substituted hydrazide 1a, 1b, 1c (10 mmol) and triethylamine $(10 \mathrm{mmol})$ in anhydrous dimethoxyethane $(40 \mathrm{~mL})$ over a period of $30 \mathrm{~min}$ at $20-25^{\circ} \mathrm{C}$. Then reaction mixture was heated to $40^{\circ} \mathrm{C}$ and stirred for $2-3 \mathrm{~h}$. The reaction was monitored by TLC. The reaction mixture was poured on ice water $(200 \mathrm{~mL})$. The obtained solid product was filtered off, washed with water and recrystallized from $80 \%$ acetic acid.

N'-[2,6-Dinitro-4-(trifluoromethyl)phenyl]-4-methoxybenzohydrazide (2a)

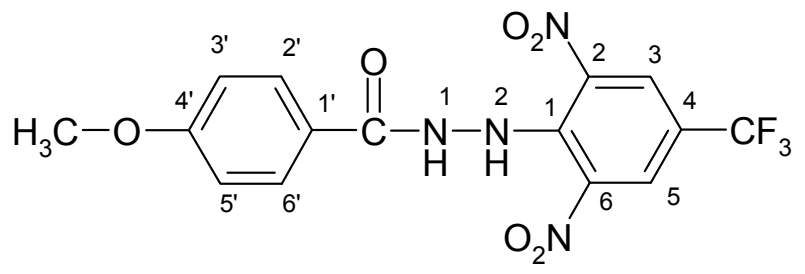

Yield 85\%; yellow solid, Mp $188-190{ }^{\circ} \mathrm{C}(80 \% \mathrm{AcOH})$. Anal. Calcd. for $\mathrm{C}_{15} \mathrm{H}_{11} \mathrm{~F}_{3} \mathrm{~N}_{4} \mathrm{O}_{6}(400.28) \mathrm{C}$, 45.01; H, 2.77: N, 14.00. Found: C, 44.92; H, 2.70; N, 13.84\%. IR: 3305 (v/NH), 1674, 1637(v/C=O), 1531, 1536 (v/NO 2$) .{ }^{1} \mathrm{H}-\mathrm{NMR} \delta: 10.75$ (s, 1H, NH-2), 9.85 (s, 1H, NH-1), 8.53 (q, 2H, $J_{(\mathrm{H}-3, \mathrm{CF} 3)}=0.5 \mathrm{~Hz}$, H-3, H-5), 7.74-7.71 (m, AA'XX', 2H, $\left.J_{(\mathrm{AX})}=8.9 \mathrm{~Hz}, \mathrm{H}-2^{\prime}, \mathrm{H}-6^{\prime}\right), 7.06-7.03$ (m, AA'XX', 2H, $\left.J_{(\mathrm{AX})}=8.9 \mathrm{~Hz}, \mathrm{H}-3^{\prime}, \mathrm{H}^{-5} 5^{\prime}\right), 3.83\left(\mathrm{~s}, 3 \mathrm{H}, \mathrm{CH}_{3}\right)$.

4-(tert-Butyl)-N'-[2,6-dinitro-4-(trifluoromethyl)phenyl]benzohydrazide (2b)

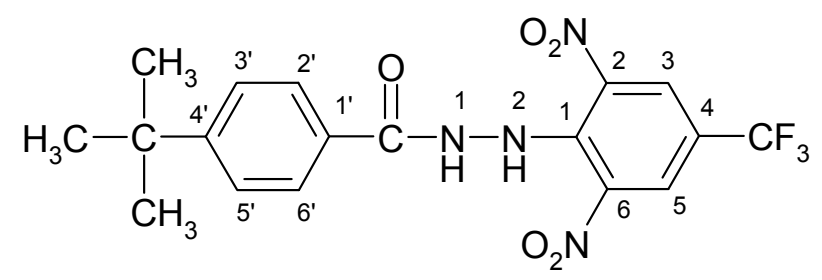


Yield 74\%; yellow solid, Mp 214-215 ${ }^{\circ} \mathrm{C}(80 \% \mathrm{AcOH})$. Anal. Calcd. for $\mathrm{C}_{18} \mathrm{H}_{17} \mathrm{~F}_{3} \mathrm{~N}_{4} \mathrm{O}_{5}$ (426.35) C, 50.71; H, 4.02: N, 13.37. Found: C, 50.66; H, 3.90; N, 13.24\%. IR: 3313 (v/NH), 1655 (v/C=O), 1505, 1542 (v/NO2). ${ }^{1} \mathrm{H}-\mathrm{NMR} \delta: 10.82$ (s, 1H, NH-2), 9.89 (s, 1H, NH-1), 8.54 (br, s, 2H, H-3, H-5), 7.70-7.67 $\left(\mathrm{m}, \mathrm{AA}^{\prime} \mathrm{XX}^{\prime}, 2 \mathrm{H}, J_{(\mathrm{AX})}=8.6 \mathrm{~Hz}, \mathrm{H}-2^{\prime}, \mathrm{H}^{\prime} 6^{\prime}\right), 7.54-7.51\left(\mathrm{~m}, \mathrm{AA}^{\prime} \mathrm{XX}^{\prime}, 2 \mathrm{H}, J_{(\mathrm{AX})}=8.6 \mathrm{~Hz}, \mathrm{H}-3^{\prime}, \mathrm{H}-5^{\prime}\right), 1.31$ $\left(\mathrm{s}, 9 \mathrm{H}, \mathrm{C}\left(\mathrm{CH}_{3}\right)_{3}\right)$.

N'-[2,6-Dinitro-4-(trifluoromethyl)phenyl]acethydrazide (2c)

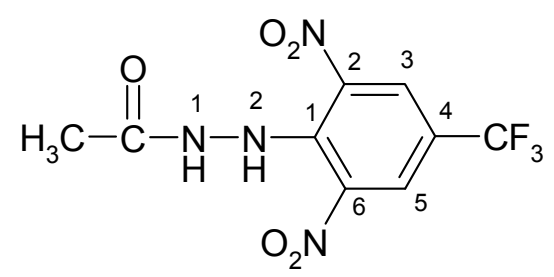

Yield 80\%; yellow solid, Mp 234-235 ${ }^{\circ} \mathrm{C}\left(80 \%\right.$ AcOH). Anal. Calcd. for $\mathrm{C}_{9} \mathrm{H}_{7} \mathrm{~F}_{3} \mathrm{~N}_{4} \mathrm{O}_{5}$ (308.18) C, 35.08; H, 2.29: N, 18.18. Found: C, 36.19; H, 2.16; N, 18.04\%. IR: 3236, 3327 (v/NH), 1674(v/C=O), 1534, 1577 (v/NO 2$) .{ }^{1} \mathrm{H}-\mathrm{NMR} \delta: 10.26$ (s, 1H, NH-2), 9.66 (s, 1H, NH-1), 8.52 (q, 2H, $J_{(\mathrm{H}-3, \mathrm{CF} 3)}=0.7 \mathrm{~Hz}$, $\mathrm{H}-3, \mathrm{H}-5), 1.76$ (s, 3H, $\left.\mathrm{CH}_{3}\right)$.

3.2.2. General Procedure for Synthesis of $N^{\prime}$-[2,6-dinitro-4-(trifluoromethyl)phenyl]hydrazonoyl Chlorides 3b, 3c, 3d, 3e

Thionyl chloride $(7 \mathrm{mmol})$ was added portionwise over a period of $20 \mathrm{~min}$ to a stirred solution (or suspension) of $N^{\prime}$-[2,6-dinitro 4-(trifluoromethyl)phenyl] hydrazides (6 mmol) $\mathbf{2 a}, \mathbf{2 b}, \mathbf{2 c}$, in toluene $(30 \mathrm{~mL})$. Then reaction mixture was heated to $70{ }^{\circ} \mathrm{C}$ over $3-4 \mathrm{~h}$. The reaction was monitored by TLC. The mixture was washed with ice water, $5 \%$ aqueous solution of sodium bicarbonate $(3 \times 10 \mathrm{~mL})$ and then with water. Organic layer was dried with anhydrous $\mathrm{Na}_{2} \mathrm{SO}_{4}$. The mixture was filtered and toluene was evaporated from the filtrate by distillation. The crude product was purified by recrystallization.

4-(tert-Butyl)-N'-[2,6-dinitro-4-(trifluoromethyl)phenyl]benzohydrazonoyl chloride (3b)

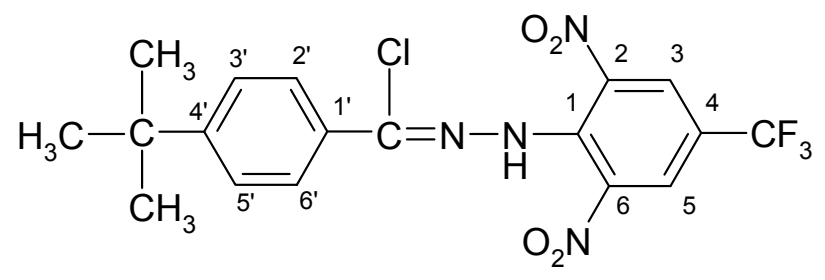

Yield 56\%; yellow solid, Mp 201-203 ${ }^{\circ} \mathrm{C}$ (cyclohexane). Anal. Calcd. for $\mathrm{C}_{18} \mathrm{H}_{16} \mathrm{ClF}_{3} \mathrm{~N}_{4} \mathrm{O}_{4}$ (444.80) C, 48.61; H, 3.63; N, 12.60. Found: C, 48.65; H, 3.48; N, 12.69\%. IR: 3427 (v/NH), 1635(v/C=O), 1570, $1571\left(\mathrm{v} / \mathrm{NO}_{2}\right) .{ }^{1} \mathrm{H}-\mathrm{NMR} \delta: 11.35(\mathrm{~s}, 1 \mathrm{H}, \mathrm{NH}), 8.73$ (q, 2H, $\left.J_{(\mathrm{H}-3, \mathrm{CF} 3)}=0.6 \mathrm{~Hz}, \mathrm{H}-3, \mathrm{H}-5\right), 7.74-7.69$ (m, $\left.\mathrm{AA}^{\prime} \mathrm{XX}^{\prime}, 2 \mathrm{H}, J_{(\mathrm{AX})}=8.8 \mathrm{~Hz}, \mathrm{H}-2^{\prime}, \mathrm{H}^{\prime} 6^{\prime}\right), 7.60-7.56\left(\mathrm{~m}, \mathrm{AA}^{\prime} \mathrm{XX}^{\prime}, 2 \mathrm{H}, J_{(\mathrm{AX})}=8.8 \mathrm{~Hz}, \mathrm{H}-3^{\prime}, \mathrm{H}-5^{\prime}\right), 1.31$ $\left(\mathrm{s}, 9 \mathrm{H}, \mathrm{C}\left(\mathrm{CH}_{3}\right)_{3}\right)$. 
$N^{\prime}$-[2,6-Dinitro-4-(trifluoromethyl)phenyl] acethydrazonoyl chloride (3c)<smiles>C/C(Cl)=N/Nc1c([N+](=O)[O-])cc(C(F)(F)F)cc1[N+](=O)[O-]</smiles>

Yield 67\%; yellow solid, Mp 97-98 ${ }^{\circ} \mathrm{C}$ (cyclohexane). Anal. Calcd. for $\mathrm{C}_{9} \mathrm{H}_{6} \mathrm{ClF}_{3} \mathrm{~N}_{4} \mathrm{O}_{4}$ (326.63) C, 33.10; H, 1.85; N, 17.15. Found: C, 33.28; H, 1.68; N, 17.27\%. IR: 3244, 3326 (v/NH), 1539, 1573 (v/NO 2$) .{ }^{1} \mathrm{H}-\mathrm{NMR} \delta: 10.96$ (s, 1H, NH), 8.66 (q, 2H, $\left.J_{(\mathrm{H}-3, \mathrm{CF} 3)}=0.5 \mathrm{~Hz}, \mathrm{H}-3, \mathrm{H}-5\right), 2.38\left(\mathrm{~s}, 3 \mathrm{H}, \mathrm{CH}_{3}\right)$.

N'-[2,6-Dinitro-4-(trifluoromethyl)phenyl]-4-fluorobenzohydrazonoyl chloride (3d)

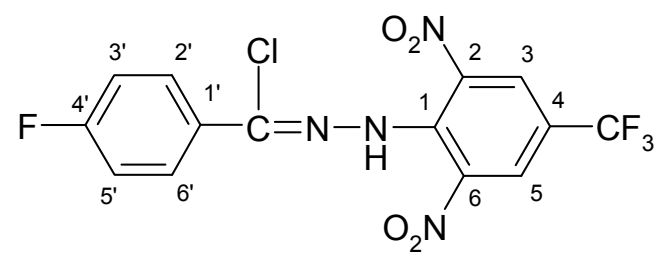

Yield 63\%; yellow solid, Mp $181-183{ }^{\circ} \mathrm{C}$ (cyclohexane). Anal. Calc. for $\mathrm{C}_{14} \mathrm{H}_{7} \mathrm{ClF}_{4} \mathrm{~N}_{4} \mathrm{O}_{4}$ (406.69) C, 41.35; H, 1.73; N, 13.78. Found: C, 41.44; H, 1.88; N, 13.79\%. IR: 3242(v/NH), 1634(v/C=N), 1534, 1577 (v/NO $\left.{ }_{2}\right) .{ }^{1} \mathrm{H}-\mathrm{NMR} \delta: 11.33(\mathrm{~s}, 1 \mathrm{H}, \mathrm{NH}), 8.73\left(\mathrm{q}, 2 \mathrm{H}, J_{(\mathrm{H}-3, \mathrm{CF} 3)}=0.5 \mathrm{~Hz}, \mathrm{H}-3, \mathrm{H}-5\right), 7.85-7.78$ (m, 2H, H-2', H-6'), 7.47-7.39 (m, 2H, H-3', H-5').

N'-[2,6-Dinitro-4-(trifluoromethyl)phenyl] thiophene-2-carbohydrazonoyl chloride (3e)

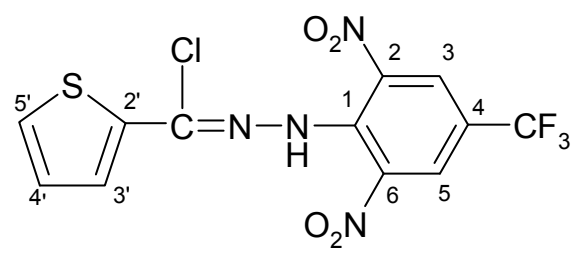

Yield 65\%; orange solid, Mp 188-189 ${ }^{\circ} \mathrm{C}$ (cyclohexane). Anal. Calc. for $\mathrm{C}_{12} \mathrm{H}_{6} \mathrm{ClF}_{3} \mathrm{~N}_{4} \mathrm{O}_{4} \mathrm{~S}$ (394.71) C, 36.52; H, 1.53; N, 14.19. Found: C, 36.62; H, 1.50; N, 13.39\%. IR: 3237(v/NH), $1633(\mathrm{v} / \mathrm{C}=\mathrm{O})$, 1537, 1580 (v/NO 2$) . ~{ }^{1} \mathrm{H}-\mathrm{NMR} \delta: 11.22$ (s, 1H, NH), 8.70 (br, s, 2H, H-3, H-5), 7.87 (dd, 1H, J=1.2 Hz, $\left.J=5.0 \mathrm{~Hz}, \mathrm{H}-5^{\prime}\right), 7.63\left(\mathrm{dd}, 1 \mathrm{H}, J=1.2 \mathrm{~Hz}, J=3.8 \mathrm{~Hz}, \mathrm{H}-3^{\prime}\right), 7.20\left(\mathrm{dd}, 1 \mathrm{H}, J=3.8 \mathrm{~Hz}, J=5.0 \mathrm{~Hz}, \mathrm{H}-4^{\prime}\right)$.

N'-[2,6-Dinitro-4-(trifluoromethyl)phenyl]-2-naphtohydrazonoyl cyanide (4f)

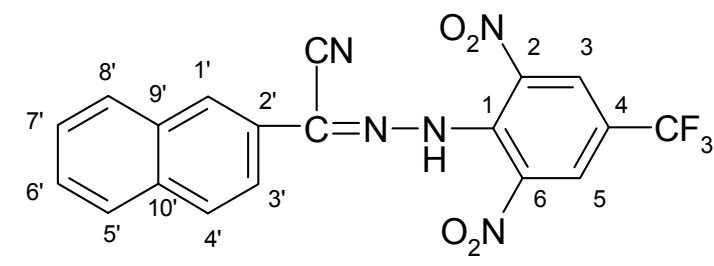

Solid $N^{\prime}$-[2,6-dinitro-4-(trifluoromethyl)phenyl]-2-naphtohydrazonoyl chloride was added portionwise over a period of $30 \mathrm{~min}$ at room temperature to a solution of potassium cyanide $(0.33 \mathrm{~g}, 5 \mathrm{mmol})$ in 
ethanol $(20 \mathrm{~mL})$ and water $(14 \mathrm{~mL})$. After that ethanol $(10 \mathrm{~mL})$ and water $(7 \mathrm{~mL})$ were added into the reaction mixture and stirred at room temperature for $12 \mathrm{~h}$. The reaction was monitored by TLC. The reaction mixture was poured into water $(30 \mathrm{~mL})$. The crude solid product was filtered, washed with water and vacuum-dried. The crude product was recrystallized from cyclohexane. Yield $1.08 \mathrm{~g} \mathrm{(63 \% );}$ yellow solid, Mp 253-255 ${ }^{\circ} \mathrm{C}$ (cyclohexane). Anal. Calc. or $\mathrm{C}_{19} \mathrm{H}_{10} \mathrm{~F}_{3} \mathrm{~N}_{5} \mathrm{O}_{4}$ (429.32) C, 53.16; H, 2.35; N, 16.31. Found: C, 52.98; H, 2.46; N, 16.50\%, IR 3232 (v/NH), 2216 (v/CN), 1525, 1537 (v/ $\left.\mathrm{NO}_{2}\right)$, 1634 (v/CN). ${ }^{1} \mathrm{H}-\mathrm{NMR} \delta: 11.88$ (br, s, 1H, NH), 8.74 (br, s, 2H, H-3, H-5), 8.26 (br, s, 1H, H-1'), 8.14-7.98 (m, 3H, H-4', H-5', H-8'), 7.71-7.63 (m, 3H, H-3', H-6', H-7').

\subsection{PET Study}

PET was monitored in spinach chloroplasts prepared according to our previous work [55]. PET through PSII was monitored by the Hill reaction with DCPIP as an artificial electron acceptor, or by using DPC as an electron donor for intermediate D in PSII [56]. PET through PSI was monitored using $\mathrm{DCPIPH}_{2}$ as an electron donor and methyl viologen as an artificial electron acceptor for PSI [56]. DCPIP photoreduction or oxidation of $\mathrm{DCPIPH}_{2}$ was determined spectrophotometrically (Genesys 6, Thermo Scientific, Waltham, MA, USA). The chlorophyll (Chl) concentration in these experiments was $30 \mathrm{mg} / \mathrm{dm}^{3}$. The inhibitory activities of the studied compounds were expressed by $\mathrm{IC}_{50}$ values, i.e., molar concentrations of the compounds causing 50\% decrease of absorbance at $600 \mathrm{~nm}$ compared to control sample. The effect of the studied compounds on the growth of the green algae Chlorella vulgaris was analyzed as described in our previous work [54].

Chlorophyll fluorescence of spinach chloroplasts was recorded at room temperature by spectrofluorimeter FSP 920 (Edinburgh Instruments, Livingston, UK) using an excitation wavelength $\lambda_{\mathrm{ex}}=436 \mathrm{~nm}$. Fluorescence of aromatic amino acids was monitored by a F-2000 spectrophotometer (Hitachi, Tokyo, Japan) using excitation wavelength $\lambda_{\mathrm{ex}}=275 \mathrm{~nm}$, according to our previous work [57]. Both fluorescence experiments were performed in $1 \mathrm{~cm}$ fluorescence cell in the right-angle arrangement. The chlorophyll concentration in chloroplast suspension was $10 \mathrm{mg} / \mathrm{dm}^{3}$.

EPR experiments were performed by the X-band EPR spectrometer (EMX Plus, Bruker, Germany) at $5 \mathrm{~mW}$ microwave power and $0.5 \mathrm{mT}$ modulation amplitude. The chloroplast suspensions were mixed with studied compounds directly before the EPR measurements and immediately transferred to a small quartz flat cell (WG 808-Q, optical cell length $0.04 \mathrm{~cm}$; Wilmad-LabGlass, Vineland, NJ, USA). The samples were irradiated at $295 \mathrm{~K}$ directly in the EPR resonator through $5 \mathrm{~cm}$ water filter, and the EPR spectra were recorded in situ during continuous photoexcitation. The irradiation source was a $150 \mathrm{~W}$ halogenated lamp. The chlorophyll concentration was $4.0 \mathrm{~g} / \mathrm{dm}^{3}$.

Due to the limited solubility of the samples, these were added to the chloroplast suspensions as a DMSO solution. DMSO at a concentration of $10 \%$ did not influence the above-mentioned photochemical reaction in the chloroplast (data not shown).

\section{Conclusions}

In this work we prepared three new $N^{\prime}$-[2,6-dinitro-4-(trifluoromethyl) phenyl)]hydrazide derivatives and five $N^{\prime}$-[2,6-dinitro-4-(trifluoromethyl)phenyl)]hydrazonoyl derivatives. Hydrazides were synthesized by nucleophilic substitution reactions of the corresponding methyl esters with hydrazine hydrate. Four 
hydrazonoyl chlorides were prepared by reaction of the corresponding $N^{\prime}$-substituted hydrazides with thionyl chloride. Starting compounds for the preparation of $N^{\prime}$-[2,6-dinitro-4-(trifluoromethyl)-phenyl]2-naphthohydrazonoyl cyanide were $N^{\prime}$-[2,6-dinitrophenyl-4-(trifluoromethyl)]-2-naphthohydrazonoyl chloride and potassium cyanide. The chemical structures of these compounds were confirmed by ${ }^{1} \mathrm{H}-\mathrm{NMR}$, IR spectroscopy and elemental analysis. The majority of compounds exhibited inhibitory effect on photosynthesis in spinach chloroplasts and on growth of the green algae Chlorella vulgaris. The $\mathrm{IC}_{50}$ values of these compounds varied in wide range, from a strong to no inhibitory effect. EPR spectroscopy showed that the active compounds interfered with intermediates $Z^{*} / \mathrm{D}^{*}$, which are localized on the donor side of PSII. Fluorescence spectroscopy suggested that the mechanism of inhibitory action of the prepared compounds possibly involves interactions with aromatic amino acids present in photosynthetic proteins.

\section{Acknowledgments}

This work was supported by the Slovak Grant Agency VEGA 1/0612/11 and VEGA 1/0041/15, the Project APVV-0061-11 and The Austrian Science Fund (FWF) grants P23609 and P21437.

\section{Author Contributions}

F.Š., F.G., P.M., D.D., K.K., M.Z. and J.D. performed experiments. F.Š., F.G., K.K. and J.G. analysed results and wrote the manuscript. All authors contributed to the paper and approved the manuscript.

\section{Conflicts of Interest}

The authors declare no conflict of interest.

\section{References}

1. Eldehna, W.M.; Fares, M.; Abdel-Aziz, M.M.; Abdel-Aziz, H.A. Design, synthesis and antitubercular activity of certain nicotinic acid hydrazides. Molecules 2015, 20, 8800-8815.

2. Gilani, S.J.; Khan, S.A.; Siddiqui, N.; Verma, S.P.; Mullick, P.; Alam, O.J. Synthesis and in vitro antimicrobial activity of novel $N$-(6-chlorobenzo[d]thiazol-2-yl) hydrazine arboxamide derivatives of benzothiazole class. J. Enzym. Inhib. Med. Chem. 2011, 26, 332-340.

3. Cacic, M.; Trkovnik, M.; Cacic, F.; Has-Schon, E. Synthesis and antimicrobial activity of some derivatives of (7-hydroxy-2-oxo-2H-chromen-4-yl)-acetic acid hydrazide. Molecules 2006, 11, 134-147.

4. Kostecka, M. Synthesis of a new group of aliphatic hydrazide derivatives and the correlations between their molecular structure and biological activity. Molecules 2012, 17, 3560-3573.

5. Patel, S.R.; Gangwal, R.; Sangamwar, A.T.; Jain, R. Synthesis, biological evaluation and 3D-QSAR study of hydrazide, semicarbazide and thiosemicarbazide derivatives of 4-(adamantan-1-yl)quinoline as anti-tuberculosis agents. Eur. J. Med. Chem. 2014, 85, 255-267.

6. Judge, V.; Narasimhan, B.; Ahuja, M.; Sriram, D.; Yogeeswari, P.; de Clercq, E.; Pannecouque, C.; Balzarini, J. Synthesis, antimycobacterial, antiviral, antimicrobial activity and QSAR studies of $N(2)$-acyl isonicotinic acid hydrazide derivatives. Med. Chem. 2013, 9, 53-76. 
7. Refat, H.M.; Fadda, A.A. Synthesis and antimicrobial activity of some novel hydrazide, benzochromenone, dihydropyridine, pyrrole, thiazole and thiophene derivatives. Eur. J. Med. Chem. 2013, 70, 419-426.

8. Mohareb, R.M.; Hana, H.Y. Synthesis of progesterone heterocyclic derivatives of potential antimicrobial activity. Acta Pharm. 2008, 58, 29-42.

9. Cui, Z.; Su, H.; Jiang, J.; Yang, X.; Nishida, Y. Design, synthesis and bioactivity of $N$-glycosyl- $N^{\prime}$ (5-substituted phenyl-2-furoyl) hydrazide derivatives. Int. J. Mol. Sci. 2014, 15, 6741-6756.

10. Ozçelik, A.B.; Gökçe, M.; Orhan, I.; Kaynak, F.; Sahin, M.F. Synthesis and antimicrobial, acetylcholinesterase and butyrylcholinesterase inhibitory activities of novel ester and hydrazide derivatives of 3(2H)-pyridazinone. Arzneimittelforschung 2010, 60, 452-458.

11. Bartzatt, R.; Cirillo, S.L.; Cirillo, J.D. Small molecule hydrazide agents to inhibit growth and proliferation of mycobacterium tuberculosis. Med. Chem. 2012, 8, 273-280.

12. Paprocka, R.; Modzelewska-Banachiewicz, B.; Wiese, M.; Eljaszewicz, A.; Michałkiewicz, J. Synthesis and anti-inflammatory activity of hydrazide derivatives of 2-methylidene-1,4-dicarboxybutanoic acid. Acta Pol. Pharm. 2012, 69, 1390-1394.

13. Rollas, S.; Küçükgüzel, S.G. Biological activities of hydrazone derivatives. Molecules 2007, 12, 1910-1939.

14. Kumar, P.; Narasimhan, B. Hydrazides/hydrazones as antimicrobial and anticancer agents in the new millennium. Mini Rev. Med. Chem. 2013, 13, 971-987.

15. Narang, R.; Narasimhan, B.; Sharma, S. A review on biological activities and chemical synthesis of hydrazide derivatives. Curr. Med. Chem. 2012, 19, 569-612.

16. Parodi, S.; de Flora, S.; Cavanna, M.; Pino, A.; Robbiano, L.; Bennicelli, C.; Brambilla, G. DNA-damaging activity in vivo and bacterial mutagenicity of sixteen hydrazine derivatives as related quantitatively to their carcinogenicity. Cancer Res. 1981, 41, 1469-1482.

17. Kak, S.N.; Kaul, B.L. Mutagenic activity of hydrazine and its combinations with maleic hydrazide and X-rays in barley. Cytobios 1975, 12, 123-128.

18. Levi, B.Z.; Kuhn, J.C.; Ulitzur, S. Determination of the activity of 16 hydrazine derivatives in the bioluminescence test for genotoxic agents. Mutat. Res. 1986, 173, 233-237.

19. Mazza, M.; Montanari, L.; Pavanetto, F. Phytotoxicity of hydrazones of aromatic aldehydes. Farmaco Sci. 1976, 31, 334-344.

20. Hendrix, J.A.; Hemmerle, H.; Urmann, M.; Shutske, G.M.; Strupczewski, J.T.; Bordeau, K.J.; Jurcak, J.G.; Nieduzak, T.R.; Jackson, S.A.; Angell, P.; et al. Novel Heterocyclic Substituted Carbonyl Derivatives and Their Use as Dopamine D3 Receptor Ligands. U.S. Patent 20090247509 A1, filed 4 November 2004, and issued 6 April 2004.

21. Saleh, M.A. Mutagenic and carcinogenic effects of pesticides. J. Environ. Sci. Health B 1980, 15, 907-927.

22. Swietlinska, Z.; Zuk, J. Cytotoxic effects of maleic hydrazide. Mutat. Res. 1978, 55, 15-30.

23. Heath, R.L. Hydrazine as an electron donor to the water-oxidation site in photosynthesis. Biochim. Biophys. Acta 1971, 245, 160-164.

24. Messinger, J.; Renger, G. Generation, oxidation by the oxidized form of the tyrosine of polypeptide D2, and possible electronic configuration of the redox states $\mathrm{S}_{0}, \mathrm{~S}_{-1}$, and $\mathrm{S}_{-2}$ of the water oxidase in isolated spinach thylakoids. Biochemistry 1993, 32, 9379-9386. 
25. Förster, V.; Junge, W. On the action of hydroxylamine, hydrazine and their derivatives on the water-oxidizing complex. Photosynth. Res. 1986, 9, 197-210.

26. Messinger, J.; Renger, G. The reactivity of hydrazine with photosystem II strongly depends on the redox state of the water oxidizing system. FEBS Lett. 1990, 277, 141-146.

27. He, P. The differences between hydroxylamine and hydrazine in affecting oxygen evolution of photosynthetic water splitting system in tobacco. Acta Phytophysiol. Sin. 1996, 22, 165-170.

28. Koske, T.J.; Svec, L.V. Some effects of maleic hyrazide on light reactions of photosynthesis in isolated chloroplasts from Phaseolus vulgaris plants. Can. J. Plant Sci. 1975, 55, 145-149.

29. Haveman, J.; Duysens, L.N.M.; van Der Geest, T.C.M.; van Gorkom, H.J. Hydrazobenzene oxidation by 2,6-dichlorophenol-indophenol in a photoreaction catalyzed by system I of photosynthesis. Hydrazine compounds as donors for photosystem II. Biochim. Biophys. Acta 1972, 283, 316-327.

30. Gasparova, R.; Zbojek, D.; Lacova, M.; Kral'ova, K.; Gatial, A.; Horvath, B.; Krutosikova, A. Reactions of substituted furo [3,2-b]pyrrole-5-carboxhydrazides and their biological activity. Cent. Eur. J. Chem. 2005, 3, 622-646.

31. Meyer, S.T.; Webster, J.D.; Young, D.H. Synergistic Algicidal Compositions Including Hydrazone Derivatives and Copper. U.S. Patent 08906829 B2, filed 18 August 2011, and issued 9 December 2014.

32. Heytler, P.G.; Prichard, W.W. A new class of uncoupling agents-carbonyl cyanide phenylhydrazones. Biochem. Biophys. Res. Commun. 1962, 7, 272-275.

33. Benz, R.; McLaughlin, S.S. The molecular mechanism of action of the proton ionophore FCCP (carbonylcyanide $p$-trifluoromethoxyphenylhydrazone). Biophys. J. 1983, 41, 381-398.

34. Avila, C.M.; Lopes, A.B.; Gonçalves, A.S.; da Silva, L.L.; Romeiro, N.C.; Miranda, A.L.; Sant'Anna, C.M.; Barreiro, E.J.; Fraga, C.A. Structure-based design and biological profile of (E)- $N$-(4-Nitrobenzylidene)-2-naphthohydrazide, a novel small molecule inhibitor of I $\mathrm{B}$ kinase- $\beta$. Eur. J. Med. Chem. 2011, 46, 1245-1253.

35. Leal, C.M.; Pereira, S.L.; Kümmerle, A.E.; Leal, D.M.; Tesch, R.; de Sant'Anna, C.M.; Fraga, C.A.; Barreiro, E.J.; Sudo, R.T.; Zapata-Sudo, G. Antihypertensive profile of 2-thienyl-3,4-methylenedioxybenzoylhydrazone is mediated by activation of the A2A adenosine receptor. Eur. J. Med. Chem. 2012, 55, 49-57.

36. Murty, M.S.R.; Ram, K.R.; Rao, R.V.; Yadav, J.S.; Rao, J.V.; Velatooru, L.R. Synthesis of new $S$-alkylated-3-mercapto-1,2,4-triazole derivatives bearing cyclic amine moiety as potent anticancer agents. Lett. Drug Des. Discov. 2012, 9, 276-281.

37. Grimster, N.P.; Connelly, S.; Baranczak, A.; Dong, J.; Krasnova, L. Aromatic sulfonyl fluorides covalently kinetically stabilize transthyretin to prevent amyloidogenesis while affording a fluorescent conjugate. J. Am. Chem. Soc. 2013, 135, 5656-5658.

38. Schwenker, G. The reaction of isonicotinic acid hydrazide with 2,4-dinitrochlorobenzene. Arch. Pharm. Ber. Dtsch. Pharm. Ges. 1958, 291, 537-541.

39. Defusco, A.A.; Strauss, M.J. Displacement-cyclization reactions of mono-substituted hydrazines with chloronitrobenzenes and chloronitropyrimidines. New routes to 8-azapurine and benzopyrazole derivatives. J. Heterocycl. Chem. 1981, 18, 351-355.

40. Karrer, F.; Hall, R.G. Cyanohydrazone Derivatives. U.S. Patent 6417386 B2, filed 13 February 2002, and issued 19 July 2002. 
41. Hemming, K.; Luheshi, A.B.N.; Redhouse, A.D.; Smaalley, R.K.; Thompson, J.R.; Kennewell, P.D.; Westwood, R. 1,3-Dipolar cycloadditions of 2-Ethoxy- and 2-(ethylthio)-1-azetines with nitrile oxides, nitrile ylides and nitrilimines: An unexpected 1,2,4-triazole formation. Tetrahedron 1993, 49, 4383-4408.

42. Huisgen, I.; Grashey, R.; Aufderhaar, E.; Kunz, R.; Siedel, M. 1.3-Dipolare Cycloadditionen, VI. Anlagerung der Nitrilimine an Azomethine und Isocyanate. Chem. Ber. 1964, 97, 1085-1095.

43. Polumbrik, O.M.; Ryabokon, I.G.; Matkovskii, L.N. Perfluorophenyl-containing verdazyl radicals. Chem. Heterocycl. Comp. 1980, 16, 882-885.

44. Doležal, M.; Miletín, M.; Kuneš, J.; Králová, K. Substituted Amides of Pyrazine-2-carboxylic acids: Synthesis and Biological Activity. Molecules 2002, 7, 363-373.

45. Gonec, T.; Kos, J.; Zadrazilova, I.; Pesko, M.; Govender, R.; Keltosova, S.; Chambel, B.; Pereira, D.; Kollar, P.; Imramovsky, A.; et al. Antibacterial and herbicidal activity of ring-aubstituted 2-hydroxynaphthalene-1-carboxanilides. Molecules 2013, 18, 9397-9419.

46. Otevrel, J.; Bobal, P.; Zadrazilova, I.; Govender, R.; Pesko, M.; Keltosova, S.; Koleckarova, P.; Marsalek, P.; Imramovsky, A.; Coffey, A.; et al. Antimycobacterial and photosynthetic electron transport inhibiting activity of ring-substituted 4-arylamino-7-chloroquinolinium chlorides. Molecules 2013, 18, 10648-10670.

47. Gonec, T.; Kos, J.; Zadrazilova, I.; Pesko, P.; Keltosova, K.; Tengler, J.; Bobal, P.; Kollar, P.; Cizek, A.; Kralova, K.; et al. Antimycobacterial and herbicidal activity of ring-substituted 1-hydroxynaphthalene-2-carboxanilides. Bioorg. Med. Chem. 2013, 21, 6531-6541.

48. Jandourek, O.; Dolezal, M.; Paterova, P.; Kubicek, V.; Pesko, M.; Kunes, J.; Coffey, A.; Guo, J.; Kralova, K. N-Substituted 5-amino-6-methylpyrazine-2,3-dicarbonitriles: Microwave-assisted synthesis and biological properties. Molecules 2014, 19, 651-671.

49. Fedtke, C. Biochemistry and Physiology of Herbicide Action; Springer Verlag: Berlin-Heidelberg, Germany; New York, NY, USA, 1982.

50. Govindjee, E. Sixty-three years since Kautsky: Chlorophyll a fluorescence. Aust. J. Plant Physiol. 1995, 22, 131-160.

51. Debus, R.J.; Barry, B.A.; Babcock, G.T.; McIntosh, L. Site-directed mutagenesis identifies a tyrosine radical involved in the photosynthetic oxygen-evolving system. Proc. Natl. Acad. Sci. USA 1988, $85,427-430$.

52. Debus, R.J.; Barry, B.A.; Sithole, I.; Babcock, G.T.; McIntosh, L. Directed mutagenesis indicates that the donor to $\mathrm{P}^{+} 680$ in photosystem II is tyrosine- 161 of the D1 polypeptide. Biochemistry $\mathbf{1 9 8 8}$, 27, 9071-9074.

53. Hoff, A.J. Application of ESR in photosynthesis. Phys. Rep. 1979, 54, 75-200.

54. Pavlíková, S.; Šeršeň, F.; Jesenák, K.; Gaplovska, K.; Č́k, G. Efficacy of modified natural zeolites in the protection against the damaging effect of 4-chlorophenol on algal growth. Fresenius Environ. Bull. 2010, 19, 3055-3058.

55. Šeršeň, F.; Balgavý, P.; Devínsky, F. Electron spin resonance study of chloroplast photosynthetic activity in the presence of amphiphilic amines. Gen. Physiol. Biophys. 1990, 9, 625-633.

56. Šeršeň, F.; Králová, K.; Macho, V. New findings about the inhibitory action of phenylcarbamates and phenylthiocarbamates on photosynthetic apparatus. Pestic. Biochem. Physiol. 2000, 68, 113-118. 
57. Šeršeň, F.; Král'ová, K; Peško, M.; Cigáň, M. Effect of $\mathrm{Pb}^{2+}$ ions on photosynthetic apparatus. Gen. Physiol. Biophys. 2014, 33, 131-136.

(C) 2015 by the authors; licensee MDPI, Basel, Switzerland. This article is an open access article distributed under the terms and conditions of the Creative Commons Attribution license (http://creativecommons.org/licenses/by/4.0/). 